\title{
20 Years of medical surveillance on exposure to allergenic and non-allergenic platinum compounds: the importance of chemical speciation
}

\author{
Peter J Linnett, E Glyn Hughes
}

\begin{abstract}
Objectives-Chloroplatinates are potent allergens but other soluble platinum compounds such as tetraammine platinum dichloride (TPC) do not provoke reactions in subjects who are sensitive to chloroplatinates. TPC has been used in the manufacture of autocatalysts for 20 years. This study analyses 20 year data on exposure to soluble platinum compounds and medical surveillance to confirm that TPC is not allergenic.
\end{abstract}

Methods-Workers in three distinct operations were exposed to soluble platinum compounds as chloroplatinates, chloroplatinates with TPC, or to TPC alone. Results of personal air sampling for soluble platinum compounds were compared together with the results of medical surveillance.

Results-The levels of exposure to soluble platinum compounds in each operation were comparable but the incidence of allergy was significantly different. In a subgroup of workers consistently exposed to chemical processes in each operation, the cumulative chance of being sensitised after 5 years of exposure was estimated as $\mathbf{5 1 \%}$ for chloroplatinate exposure, $33 \%$ for mixed exposure, and $0 \%$ for TPC alone. The differences in sensitisation rates could not be explained by age, sex, and atopy. Nor could they be explained by the increased frequency of smoking in the workers with chloroplatinate exposure, despite the markedly higher risk of sensitisation in smokers. The differences could only be explained by the chemical stability of TPC. Conclusions-This study shows that the soluble platinum compound TPC is not allergenic under normal industrial conditions. Characterisation of the chemical compound (speciation) is essential to prevent stringent exposure limits being imposed for all soluble compounds on a generic basis.

(Occup Environ Med 1999;56:191-196)

Keywords: allergy; platinum; tetraammine platinum chloride

Allergy to the complex halogenated salts of platinum is a serious problem in the refining of platinum group metals (PGMs) and use of platinum compounds. ${ }^{1-7}$ Less hazardous platinum compounds are needed as alternatives to the halogenated complexes. The allergic mechanism is a type I reaction ${ }^{8}$ and a skin prick test with chloroplatinate salts such as ammonium hexachloroplatinate $\left(\mathrm{NH}_{4}\right)_{2} \mathrm{PtCl}_{6}$ has been used for the diagnosis of the allergy. ${ }^{9}$ Skin prick testing is an integral part of the medical surveillance of workers exposed to these compounds. ${ }^{1011}$

In a study of 22 different platinum compounds 10 subjects who had positive skin prick tests to chloroplatinates plus two control subjects underwent skin prick tests. ${ }^{12}$ The allergenic potential was shown to be related to the number of leaving halide ligands in the complex salts and thus to the reactivity of the compound. No reaction was provoked by neutral platinum compounds or salts with no halide ligands.

Tetraammine platinum dichloride $\left[\left(\mathrm{NH}_{3}\right)_{4} \mathrm{Pt}\right] \mathrm{Cl}_{2}$ (TPC) is a complex salt in which the halide is present as an ion and not as a ligand coordinated to platinum. It does not provoke a reaction on skin prick tests in subjects who are allergic to chloroplatinates ${ }^{12}$ and it has been used by Johnson Matthey in the United Kingdom since 1975 for the manufacture of autocatalytic converters. It is a soluble platinum compound according to the test method used for determination of exposure ${ }^{13}$ which has therefore been subject to the same occupational exposure standard that applies to chloroplatinates, and workers exposed to TPC have been subject to regular medical surveillance. This retrospective study was made as a response to the proposal that a maximum exposure limit of $2 \mu \mathrm{g} \cdot \mathrm{m}^{-3}$ should be applied in the United Kingdom to all soluble platinum compounds. ${ }^{14}$ It reports the results of 20 years medical surveillance of workers in three distinct operations who were exposed to soluble platinum as chloroplatinates only, as chloroplatinates and TPC, and as TPC only.

\section{Methods and materials}

STUDY POPULATION

The study is a retrospective analysis of the results of medical surveillance at a major United Kingdom platinum company of all new employees who started work between 1 January 1976 and 31 December 1995 and who were followed up until 31 December 1995. They worked in one of three operations on the same site designated in this report as the platinum group metals refinery (PGM refinery), TPC production laboratory (TPC lab), and autocatalyst production (Autocat). The criteria for inclusion 
Table 1 Characteristics of the study population and subgroup of chemical process operators (CPOs)

\begin{tabular}{|c|c|c|c|}
\hline & PGM refinery & $T P C l a b$ & Autocat \\
\hline \multicolumn{4}{|l|}{ Total population: } \\
\hline Subjects (n) & 406 & 41 & $100+$ \\
\hline Age (mean (range)) & $29.0(17.7-61.4)$ & $24.6(16.8-47.0)^{\star \star}$ & $25.5(15.9-60.5)^{\star \star \star}$ \\
\hline Smokers $(\mathrm{n}(\%))$ & $199(49.0)$ & $11(26.8)^{\star \star}$ & $33(33.7)^{\star \star}$ \\
\hline Men & 373 & 40 & 85 \\
\hline Women (n (\%)) & $(8.1)$ & $1 \quad(2.4)$ & $(15.0)$ \\
\hline Atopic & 1 & 0 & 4 \\
\hline \multicolumn{4}{|l|}{ CPOs: } \\
\hline Subjects (n) & 270 & 31 & $40 \ddagger$ \\
\hline Age (mean (range)) & $30.3(17.7-59.0)$ & $24.6(16.8-47.0)^{\star \star \star}$ & $28.8(15.9-60.5)^{\star}$ \\
\hline Smokers $(\mathrm{n}(\%))$ & $164(60.7)$ & $9(29.0)^{\star \star}$ & 17 (43.6) \\
\hline Men & 257 & 31 & 40 \\
\hline Women (n (\%)) & $(4.8)$ & $(0.0)$ & $(0.0)$ \\
\hline Atopic & 0 & 0 & 0 \\
\hline
\end{tabular}

${ }^{\star} \mathrm{p}<0.05 v$ TPC lab; ${ }^{\star \star} \mathrm{p}<0.01$ and ${ }^{\star \star} \mathrm{p}<0.001 v$ PGM refinery.

†One subject with no data on age, two with no data on smoking.

¥One CPO with no data on smoking. which was rich in the platinum group metals (platinum, palladium, rhodium, iridium, ruthenium, and osmium) plus gold. The process involved dissolution of the precious metals in aqua regia or concentrated hydrochloric acid and chlorine with final precipitation of platinum as ammonium hexachloroplatinate which was then thermally reduced to metal. ${ }^{10}$ In 1988 the input changed to PGMs for secondary refining by the same technology. The secondary material was richer in platinum than the primary feed had been. Due to the nature of the process all stages in the refining operation were contaminated by chloroplatinates. Soluble platinum measured in air samples was entirely due to airborne chloroplatinates. Employees in the refinery were exposed to chloroplatinates but not to TPC. Chloroplatinic acid $\left(\mathrm{H}_{2} \mathrm{PtCl}_{6}\right)$ was produced in this building and delivered in clean sealed containers to the TPC lab for conversion to TPC.

required (a) that they had no previous exp to soluble platinum compounds, (b) during their work they had regular exposure to soluble platinum compounds which required them to be subject to medical surveillance, and $(c)$ they remained in employment long enough to have attended for at least one medical examination. All subjects had a pre-employment medical examination before recruitment and the occupational health unit was notified when they started work. Atopic subjects, shown by a positive reaction on skin prick test to common allergens (cat fur, house dust mite, or grass pollen) $\geqslant 2 \mathrm{~mm}$ in diameter greater than the response to glycerol carbol saline the negative control, were not employed in production jobs. Five atopic subjects were employed in secretarial and administrative positions.

Subjects who transferred between operations were considered to have withdrawn from the study at the date of transfer and were not included in the analysis for the operation to which they transferred. The study population comprised 406 employees in the PGM refinery, 41 in the TPC lab and 100 in the Autocat; 53 vacation students who worked in the Autocat for up to 8 weeks in service functions-for example, the warehouse-and whose potential exposure to airborne soluble platinum was minimal have not been included. The three operations were in separate self contained buildings. Table 1 shows the number and characteristics of the subject: age, smoking, when they started work, sex, and atopy. The PGM refinery was self supporting for most of its services which included instrumentation and laundry. As several jobs in the PGM refinery were not replicated in the other two operations the chemical process operators (CPOs), being exposed to soluble platinum for at least $50 \%$ of their work, were identified and are shown as a subgroup in table 1 . As the work and potential for exposure to airborne soluble platinum for CPOs was similar in the three operations the exposures, characteristics, and sensitisation of this subgroup were examined further.

WORKPLACE EXPOSURES

Platinum group metals refinery (PGM refinery)

This refinery started operation in 1958 as a primary refinery for concentrate from South Africa

\section{TPC production laboratory (TPC lab)}

TPC production took place in a laboratory in which various compounds of platinum and the other PGMs were produced. The starter compound for TPC was chloroplatinic acid received from the PGM refinery. This was treated in a closed reactor vessel to produce TPC either in solution or as a dried powder. Powdered TPC was sieved in a draughted fume cabinet but because of the dry nature of the product and its tendency to deposit as a dust respiratory protection was worn during this operation. Soluble platinum measured in air samples was considered to be a mixture of chloroplatinate and TPC although the highest values occurred in sieving of dry TPC. The TPC produced in this laboratory was delivered as a solution to the Autocat. From 1974 all employees in the TPC lab had regular exposure to soluble platinum compounds.

\section{Autocatalyst production (Autocat)}

Autocatalysts were produced by coating a ceramic or metal honeycomb (substrate) with an alumina based washcoat in which other metal compounds may be incorporated-for example, cerium acetate. The coated substrate was dried in an oven, impregnated with a solution rich in compounds of platinum, palladium, or rhodium and then fired to achieve thermal reduction of the metal compounds. Autocatalyst production started in 1974. Chloroplatinic acid was initially used as one of the platinum compounds but from mid-1975 onwards only the tetraammine compounds were used. Soluble platinum measured in air samples was entirely due to airborne TPC.

\section{Monitoring and analysis of airborne soluble \\ platinum}

Sampling for airborne soluble platinum over the study used personal and static samplers as well as wipe tests for settled dusts to check that control was adequate and to identify tasks and situations where improved control was needed. Strategies in the three operations varied, in the PGM refinery there was a bias towards sampling for tasks of short duration to identify 
Table 2 Exposure to airborne soluble platinum for 1976-95 (whole group) and from 1988-91 (CPOs only)

\begin{tabular}{llll}
\hline & PGM refinery & TPC lab & Autocat \\
\hline 1976-95 Whole group: & & & \\
Total samples & 8573 & 511 & 453 \\
$\mathrm{n} \geqslant 2 \mu \mathrm{g} \cdot \mathrm{m}^{-3}(\%)$ & $436(5.1)$ & $247(48.3)^{\star \star \star}$ & $130(28.7)^{\star \star \star}+\mathrm{t}+$ \\
Maximum & 236 & 6500 & 438 \\
1989-91 CPO only: & & & \\
Total samples & 380 & 130 & 176 \\
$\mathrm{n} \geqslant 2 \mu \mathrm{g} \cdot \mathrm{m}^{-3}(\%)$ & $9(2.4)$ & $37(28.5)^{\star \star \star}$ & $15(8.5)^{\star \star}+\mathrm{t}+$ \\
Distribution $(\mathrm{cumulative} \mathrm{\% ):}$ & & & \\
$<0.5 \mu \mathrm{g} \cdot \mathrm{m}^{-3}$ & $335(88.2)$ & $67(51.5)$ & $107(60.8)$ \\
$0.5-<1.0 \mu \mathrm{g} \cdot \mathrm{m}^{-3}$ & $21(93.7)$ & $12(60.8)$ & $38(82.4)$ \\
$1.0-<2.0 \mu \mathrm{g} \cdot \mathrm{m}^{-3}$ & $15(97.6)$ & $14(71.5)$ & $16(91.5)$ \\
$2.0-<5.0 \mu \mathrm{g} \cdot \mathrm{m}^{-3}$ & $7(99.5)$ & $25(90.8)$ & $10(97.2)$ \\
$5.0-<10.0 \mu \mathrm{g} \cdot \mathrm{m}^{-3}$ & $1(99.7)$ & $9(97.7)$ & $2(98.3)$ \\
$>10.0 \mu \mathrm{g} \cdot \mathrm{m}^{-3}$ & $1(100.00)$ & $3(100.00)$ & $3(100.0)$ \\
\hline
\end{tabular}

${ }^{\star \star} \mathrm{p}<0.01 ;{ }^{\star \star \star} \mathrm{p}<0.001 v$ PGM refinery.

$+\dagger+\mathrm{p}<0.001 v$ TPC Lab. work. In one worker who was skin prick test negative the diagnosis was confirmed by specific bronchial challenge at the Royal Brompton Hospital.

The criteria for diagnosis of allergy to platinum salts required one or more of $(a)$ a repeatable positive reaction to one of the chloroplatinate salts on skin prick test, (b) a positive response to specific bronchial challenge, (c) demonstration of work related symptoms and signs by the occupational physician by monitoring spirometry and records of peak expiratory flow or direct observation of rhinorrhoea and upper respiratory symptoms, or (d) positive patch test. In all cases a recommendation was made to end exposure. The date of diagnosis was recorded as the date of the first positive skin prick test, specific bronchial challenge, or when these were negative the date of the recommendation by the occupational physician to end exposure. running and not as an 8 hour time weight average ( $8 \mathrm{~h}$ TWA). In the TPC lab and the Autocat samples were collected for a whole shift and are reported as an $8 \mathrm{~h}$ TWA. For this study to achieve comparability between the measurements made in the three operations only the results of personal samples have been presented. Samples were collected on a $25 \mathrm{~mm}$ filter with a seven hole sampling device and pump running at $2 \mathrm{l} / \mathrm{min}$. Filters were dissolved in $0.12 \mathrm{M} \mathrm{HCl}$ and analysed by electrothermal AA spectrophotometry.

MEDICAL SURVEILLANCE ROUTINES

All subjects were medically examined before employment and satisfied the standards for work with soluble platinum compounds. ${ }^{10}{ }^{11}$ Atopic subjects identified by history or a positive reaction on skin prick test to common aeroallergens were not employed in production or technical positions. Smoking habit was recorded before employment. Smokers were not excluded but smoking was not permitted in any area where soluble platinum compounds were handled. The medical surveillance routine comprised enquiry about symptoms and skin prick tests every 3 months with three platinum salts in glycerol carbol saline, these were ammonium hexachloroplatinate $\left(\mathrm{NH}_{4}\right)_{2} \mathrm{PtCl}_{6}$, sodium hexachloroplatinate $\mathrm{Na}_{2} \mathrm{PtCl}_{6}$, and sodium tetrachloroplatinite $\mathrm{Na}_{2} \mathrm{PtCl}_{4}$ at a concentration of $10^{-3} \mathrm{~g} \cdot \mathrm{ml}^{-1}$. Spirometry was performed every 6 months with a Vitalograph single breath dry wedge bellows. The skin prick tests were read as positive if the diameter of the weal produced by one of the platinum salts was $\geqslant 2 \mathrm{~mm}$ greater than that produced by the negative control solution (glycerol carbol saline). All positive reactions were confirmed by repeat testing with serial dilutions of the platinum salts. In 1992 the sodium tetrachloroplatinite was replaced by $10^{-3} \mathrm{~g} \cdot \mathrm{ml}^{-1}$ TPC in $0.9 \%$ sodium chloride. In 1994 the ammonium hexachloroplatinate and sodium hexachloroplatinate in glycerol carbol saline were replaced by sodium hexachloroplatinate at $10^{-3} \mathrm{~g} \cdot \mathrm{ml}^{-1}$ in $0.9 \%$ sodium chloride. Employees who presented with symptoms were examined by skin prick test and if this was negative they were monitored by spirometry and peak expiratory flow to establish if there was a relation with

\section{STATISTICAL ANALYSIS} operations were analysed with one way analysis of variance (ANOVA). Differences in smoking habits and in the results of air sampling were analysed with Fisher's exact test. Comparisons between age groups, smoking groups, and sitisation were analysed with the Peto log rank method, showing inverse Kaplan-Meier plots of the distribution of time to onset.

\section{Results}

\section{EXPOSURE DATA}

Table 2 shows the composite results for each operation with the maximum value and numbers in excess of $2.0 \mu \mathrm{g} . \mathrm{m}^{-3}$ which was the exposure limit.

In the PGM refinery 8573 samples were collected of which 436 were $\geqslant 2 \mu \mathrm{g} \cdot \mathrm{m}^{-3}$. From 1978 to 1982 the records showed only the number of samples collected and values were available only for those results $\geqslant 2 \mu \mathrm{g} \cdot \mathrm{m}^{-3}$; in other years values above the limit of detection were reported, for short term sampling this was $0.5 \mu \mathrm{g} . \mathrm{m}^{-3}$ and for full shift sampling $0.2 \mu \mathrm{g} . \mathrm{m}^{-3}$ . In the TPC lab, 511 samples were collected in the years 1977-95 of which 247 (48.3\%) were $\geqslant 2$. In the Autocat 453 samples were collected from 1977-95, of which 130 (28.7\%) were $\geqslant 2$.

The results show that levels of exposure were the PGM refinery. From 1988 to 1991 the programmes for monitoring exposure in the three operations were stable and there were no major changes in the processes. Composite results over these 4 years for CPOs eligible for inclusion in this study are shown in more detail in table 2. Concentrations were lowest in the PGM refinery where almost $90 \%$ of the samples were $<0.5 \mu \mathrm{g} \cdot \mathrm{m}^{-3}$ and only $2.4 \%$ were $>2 \mu \mathrm{g} . \mathrm{m}^{-3}$. They were highest in the TPC lab, where almost half the samples were $>0.5 \mu \mathrm{g} . \mathrm{m}^{-3}$ and $28.5 \%$ were $>2 \mu \mathrm{g} . \mathrm{m}^{-3} \quad(\mathrm{p}<0.001 v$ the PGM refinery). Concentrations in the Autocat were intermediate.
Differences in age between workers in the three workers in the three operations for time to senhigher in the TPC lab and the Autocat than in 
Table 3 Cumulative probability of sensitisation and rate by operation (unadjusted for cigarette smoking or age at start of employment)

\begin{tabular}{llll}
\hline & PGM refinery & TPC lab & Autocat \\
\hline Total population: & & & 100 \\
$\quad$ Subjects (n) & 406 & 41 & 0 \\
$\quad$ Cases & 110 & 5 & 40 \\
CPOs: & 270 & 31 & 0 \\
$\quad$ Subjects (n) & 106 & 5 & 15.25 \\
$\quad$ Cases observed & 83.89 & 11.86 & $0.00^{\star \star \star}+$ \\
$\quad$ Cases expected & 1.00 & $0.33^{\star}(0.14-0.78)$ & 0.00 \\
$\quad$ Relative risk (95\% CI) & 0.22 & 0.03 & 0.00 \\
Risk of becoming sensitive by employment year: & 0.38 & 0.07 & \\
$\quad$ & 0.51 & 0.33 & 0.00 \\
$\quad$ Rate of sensitisation (cases/100 person-months & & 0.5 & N/A \\
$\quad$ during the first 5 years of employment) & 1.4 & $36.9(7.1-51.7)$ & \\
Median time to diagnosis (months) & $12.6(1.0-107.9)$ & & \\
\hline
\end{tabular}

${ }^{\star} \mathrm{p}<0.05 ;{ }^{\star \star \star}{ }_{\mathrm{p}}<0.001 v$ PGM refinery.

tp $<0.05 v$ TPC lab.

$\ddagger$ Based on a logrank test assuming risk of becoming sensitive depends on time of employment but not operation.

MEDICAL SURVEILLANCE

Table 3 compares rates of sensitisation in the three operations in the total population, and in more detail, in the CPOs. Figure 1 plots the cumulative probability of sensitisation by month of employment in CPOs in the three operations.

In the PGM refinery there were 110 cases among the 406 employees. Of these 100 were skin prick test positive, and of the 10 skin prick test negative cases one was patch test positive, one was positive on bronchoprovocation, seven had demonstrable bronchospasm at work, and one had demonstrable work related upper respiratory symptoms. In the subgroup of $270 \mathrm{CPOs,}$ 106 were sensitised with a median time to diagnosis of 12.6 months (range 1.0-107.9 months). Of the cases $80(75 \%)$ were sensitised in the first 2 years of employment. The cumulative probability of sensitisation in CPOs was $22 \%$ by year $1,28 \%$ by year 2 , and $51 \%$ by year 5 . The rate of

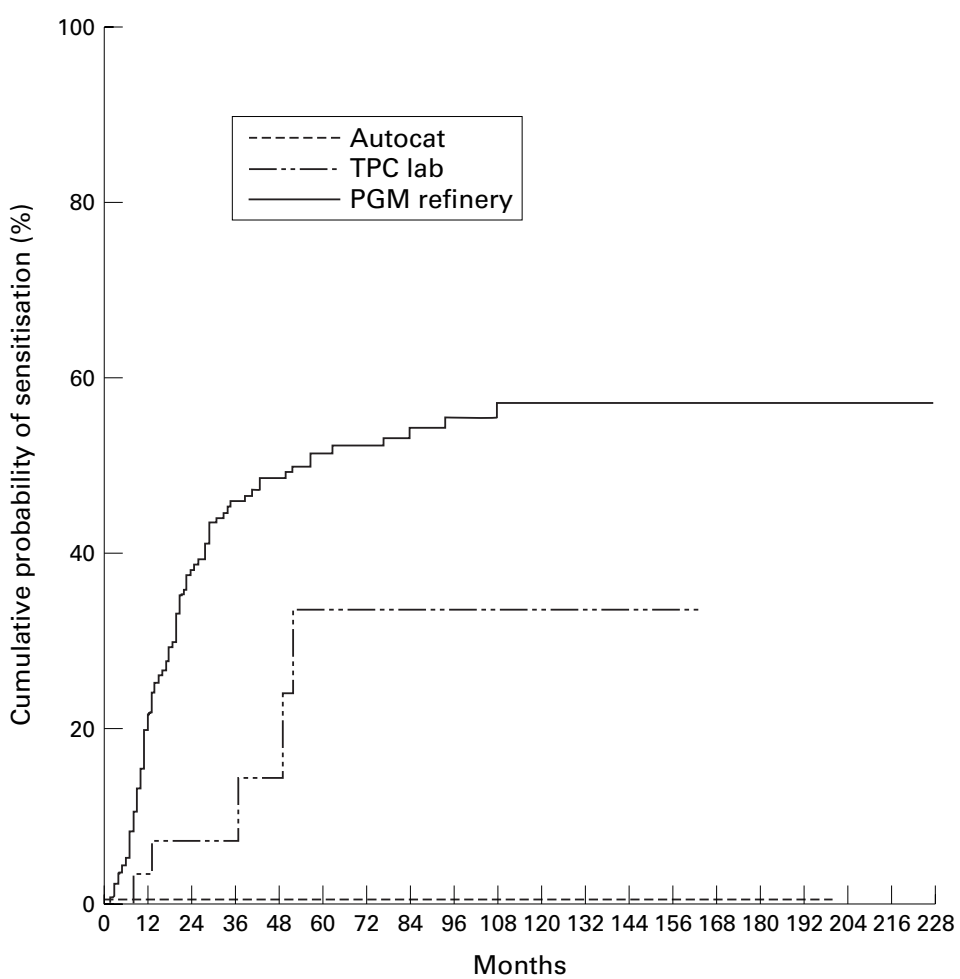

Figure 1 Cumulative probability (\%) of sensitisation by months of employment in CPOs in the three operations. Lines stop at the longest period of employment in the relevant group. sensitisation in CPOs, expressed as cases per 100 person-months during the first 5 years of employment, was 1.4. Eleven employees (eight CPOs) transferred to the Autocat.

In the TPC lab there were five cases among the 41 subjects. All the workers were CPOs, with four skin prick test positive and one skin prick test negative with demonstrable respiratory symptoms. Median time to diagnosis was 36.9 months (range 7.1-51.7 months). The cumulative probability of sensitisation in CPOs was $3 \%$ by year $1,7 \%$ by year 2 , and $33 \%$ by year 5. Based on the Peto log rank test, the probability of sensitisation was significantly less than that in the PGM refinery $(\mathrm{p}<0.005)$. The rate of sensitisation in CPOs was estimated as 0.5 cases per 100 person-months. One CPO transferred to the PGM refinery.

In the Autocat there were no cases of allergy and no positive skin prick test reactions to chloroplatinates or TPC among the 100 workers, 40 of whom were CPOs. The probability of sensitisation in CPOs was highly significantly less than in the PGM refinery $(p<0.001)$ and significantly less than in the TPC lab $(p<0.05)$. One CPO transferred to the PGM refinery.

Table 4 investigates the relation of age at the start of employment and number of cigarettes smoked a day to probability of sensitisation in CPOs in the PGM refinery. There was no evidence at all of a relation with age, but strong evidence of a relation with cigarette smoking. Compared with non-smokers risk was an estimated 2.19 times higher in smokers of 1-19 cigarettes a day $(\mathrm{p}<0.01)$ and 3.24 times higher in smokers of $\geqslant 20$ cigarettes a day $(p<0.001)$. Figure 2 plots the cumulative probability of sensitisation by month of employment for the three smoking groups. By the end of the first year, $8 \%$ of non-smokers, $27 \%$ of smokers of 1-19 cigarettes a day, and $35 \%$ of smokers of $\geqslant 20$ cigarettes a day had become sensitised. By the end of year 2 , the corresponding figures were $25 \%, 38 \%$, and $56 \%$ and by the end of year 5 they were $31 \%, 57 \%$, and $71 \%$.

Because of the possible confounding effect of smoking, unadjusted comparisons of CPOs in the three operations shown in table 3 were repeated taking account of smoking (table 5). In all three groups of smokers risk was highest in the PGM refinery, intermediate in the TPC 
Table 4 Relation of age at start of employment and smoking to risk of sensitisation to CPOs in the PGM refinery

\begin{tabular}{llllll}
\hline Factor & $\begin{array}{l}\text { Subjects } \\
(n)\end{array}$ & $\begin{array}{l}\text { Cases } \\
\text { observed }\end{array}$ & $\begin{array}{l}\text { Cases } \\
\text { expected }\end{array}$ & $\begin{array}{l}\text { Relative risk (95\% } \\
\text { CI) }\end{array}$ & $\begin{array}{l}\text { p Value for } \\
\text { trend }\end{array}$ \\
\hline Age: & & & & & \\
$15-24$ & 91 & 34 & 34.85 & 1.00 & \\
$25-34$ & 106 & 42 & 39.85 & $1.09(0.69$ to 1.73$)$ & NS \\
$\begin{array}{l}35+ \\
\text { Cigarettes a day: }\end{array}$ & 73 & 30 & 31.31 & $0.98(0.59$ to 1.63$)$ & \\
$\quad 106$ & 26 & 47.89 & 1.00 & \\
$1-19$ & 106 & 40 & 34.67 & $2.19(1.34$ to 3.58) & \\
$\geqslant 20$ & 92 & 40 & 23.44 & $3.24(2.00$ to 5.25) & $<0.001$ \\
\hline
\end{tabular}

^If risk of sensitisation depends on time of employment and not factor studied.

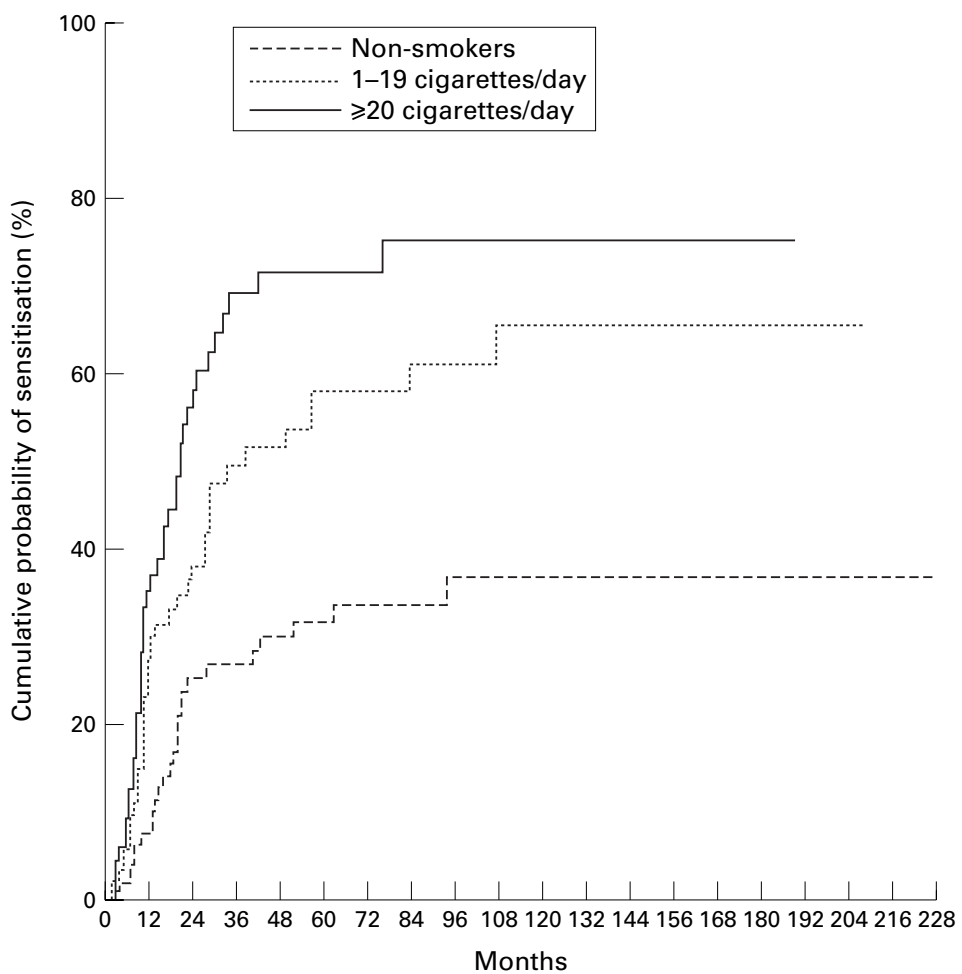

Figure 2 Cumulative probability (\%) of sensitisation by months of employment and cigarette smoking in the PGM refinery. Lines stop at the longest period of employment in the group.

Table 5 Rates of sensitisation in CPOs by subgroup after adjustment for cigarette smoking

\begin{tabular}{|c|c|c|c|}
\hline & $\begin{array}{l}P G M \\
\text { refinery }\end{array}$ & TPC lab & Autocat \\
\hline \multicolumn{4}{|l|}{ Non-smokers: } \\
\hline Subjects (n) & 106 & 22 & 22 \\
\hline Cases observed & 26 & 1 & 0 \\
\hline Cases expected $\dagger$ & 18.86 & 4.15 & 3.99 \\
\hline Relative risk & 1.00 & 0.18 & $0.00^{\star}$ \\
\hline \multicolumn{4}{|c|}{ Smokers of $1-19$ cigarettes a day: } \\
\hline Subjects (n) & 92 & 7 & 9 \\
\hline Cases observed & 40 & 3 & 0 \\
\hline Cases expected $\dagger$ & 35.50 & 3.47 & 4.03 \\
\hline Relative risk & 1.00 & 0.76 & 0.00 \\
\hline \multicolumn{4}{|c|}{ Smokers of $\geqslant 20$ cigarettes a day: } \\
\hline Subjects (n) & 72 & 2 & 8 \\
\hline Cases observed & 40 & 1 & 0 \\
\hline Cases expected $\ddagger$ & 33.37 & 1.07 & 6.56 \\
\hline Relative risk & 1.0 & 0.79 & $0.00^{\star \star}$ \\
\hline \multicolumn{4}{|c|}{ Combined (adjusted for cigarette smoking): } \\
\hline Subjects (n) & 270 & 31 & 39 \\
\hline Cases observed & 106 & 5 & 0 \\
\hline Cases expected $\ddagger$ & 87.73 & 8.69 & 14.59 \\
\hline Relative risk ( $95 \%$ CI) & 1.00 & $0.47(0.20$ to 1.12$)$ & $0.00^{\star \star \star}$ \\
\hline
\end{tabular}

${ }^{\star} \mathrm{p}<0.05 ;{ }^{\star \star} \mathrm{p}<0.01 ;{ }^{\star \star \star}{ }^{\star} \mathrm{p}<0.001 v$ PGM refinery.

$\dagger$ If risk of sensitisation depends on time of employment, but not operation.

¥If risk of sensitisation depends on time of employment and cigarette smoking, but not operation.

lab and lowest in the Autocat. Based on the combined data, the lower risk in the Autocat than in the PGM refinery remained highly sig- nificant $(\mathrm{p}<0.001)$. Adjustment for smoking, however, removed the significance of the difference between the PGM refinery and the TPC lab, increasing the unadjusted relative risk estimate of 0.33 (95\% confidence interval ( $95 \% \mathrm{CI}) 0.14$ to 0.78 ) to 0.47 (0.20 to 1.12 ).

Conclusions were unaffected by omitting the relatively few women from the analysis.

\section{Discussion}

This is the first study to report on the use of TPC. It confirms the allergenic potential of the complex halogenated salts of platinum and shows the lack of effect attributable to TPC alone. This supports the interpretation of Cleare et $a l^{12}$ who showed that TPC did not provoke a reaction on skin prick tests in subjects who were sensitive to chloroplatinates. The incidence of allergy to chloroplatinates in chemical process workers in the PGM refinery at 1.4 cases per 100 person-months (cphpm) was of the same order as that reported by Venables et $a l^{\bar{l}}$ of an earlier cohort from the same refinery (between 2.4 and $6.8 \mathrm{cphpm}$ ), by Calverly $e t a l^{6}$ at a similar refinery in South Africa (2.7 cphpm) and by Niezborala and Garnier at a refinery in France $(0.73 \mathrm{cphpm}){ }^{7}$ Incidences can be distorted by the proportion of long serving unsensitised long term survivors in the workforce so this method is not appropriate for comparison of performance, which is better done with cumulative probability of sensitisation. In this study there were proportionately more long term survivors in the TPC lab and the Autocat than in the PGM refinery so the incidences were calculated only for the first 60 months of employment. Statistical analysis taking into account the survivors confirmed that in the Autocat the zero rate was highly significantly $(\mathrm{p}<0.001)$ less than that in the PGM refinery. Rates in the TPC lab were intermediate.

The possibility has to be considered that subjects who were only exposed to TPC would not react to chloroplatinates on skin prick test even though they were sensitive to TPC itself. None of the employees from the Autocat presented with symptoms of a type I allergy that could be attributed to their work, and since the skin prick test to TPC was introduced into the routine surveillance in 1992 none have shown a positive reaction to it. It is our experience that about half of the workers identified by a positive skin prick test at routine surveillance already have work related symptoms and the others will develop symptoms, usually within 3 months, if the same level of exposure is maintained. Thus any worker with allergy to TPC should have presented with symptoms at routine surveillance and on this basis we are confident that there were no cases of allergy which could be attributed to TPC and were missed because skin prick test to TPC was not performed.

Risk factors for developing the allergy are levels of exposure to platinum salts, ${ }^{6}$ smoking, ${ }^{5-7}{ }^{15}$ and atopy. ${ }^{5}$ These variables have been considered to see if they account for the difference in the incidence and risk of developing the allergy. 
In the refining process ammonium hexachloroplatinate is regarded as insoluble and this allows for its precipitation from the liquors, however, its solubility is $7 \mathrm{~g} / 1$ and during personal air sampling over one shift about $0.002 \mathrm{mg}$ platinum will be collected at the exposure limit of $0.002 \mathrm{mg} . \mathrm{m}^{-3}$. This amount is soluble in the $5.0 \mathrm{ml} 0.07 \mathrm{M} \mathrm{HCl}$ used for extraction of samples from the filters. The solubility of TPC is $200 \mathrm{~g} / 1$ so it is readily soluble in the test method. The analytical technique for measurement of soluble platinum in the air samples at this site used $0.12 \mathrm{M} \mathrm{HCl}$ $(1.0 \% \mathrm{v} / \mathrm{v})$ compared with $0.07 \mathrm{M}$ recommended in the method for the determination of hazardous substances $46^{13}$ which might have a minimal effect of increasing the recovery of poorly soluble platinum compounds. This technique cannot differentiate the chemical species. Exposures to soluble platinum (chloroplatinate and TPC) compounds in the TPC lab and in the Autocat were higher than in the PGM refinery shown by the proportion of results above the exposure limit and maximum values. These differences could not be attributed to the different solubilities of the platinum compounds.

The monitoring programme in the PGM refinery was more intensive than in the other operations and with short term sampling periods it was designed to identify situations of poor control during specific processing tasks. The number of samples collected in the PGM refinery gives confidence that the true exposure levels were not underestimated.

As atopic subjects were excluded from employment as CPOs this could not be considered as a risk factor in this study. Smoking was confirmed to be a risk factor as in previous reports. Adjustment for smoking did not affect the conclusion that rates were highly significantly lower in the Autocat than in the PGM refinery $(p<0.001)$. However, it somewhat affected the conclusion that rates were lower in the TPC lab than in the PGM refinery, increasing a significant unadjusted relative risk of $0.33(\mathrm{p}<0.05)$ to a non-significant smoking adjusted relative risk of 0.47 . It should be noted, however, that although there was a higher frequency of smokers in the PGM refinery, the proportion of non-smokers sensitised was higher in the PGM refinery $(24.5 \%)$ than in the TPC lab $(4.5 \%)$ or in the Autocat $(0 \%)$.

In the PGM refinery employees had regular exposure to irritant gases and fumes-for example, chlorine-less so in the TPC lab and minimally in the Autocat. It has been conjectured that such exposure may be a risk factor but the records did not allow this to be studied. Fume releases from processes in the PGM refinery were invariably accompanied by chloroplatinates and pure exposure to chlorine was a rare occurrence.

This supports the original study, ${ }^{12}$ which showed a lack of response to TPC in subjects who were sensitive to chloroplatinates and shows that TPC is not a sensitiser. As a low molecular weight ion, hexachloroplatinate $\left[\mathrm{PtCl}_{6}\right]^{2-}$ must act as a hapten to form an antigen and the probable adjunct is human serum albumin (HSA). ${ }^{16}$ In chloroplatinate ions there are comparatively labile leaving groups (chloride ions) which allow substitution by sulphur or nitrogen containing ligands to occur within a biologically relevant time scale. The most likely bond is to the sulphur in methionine groups in HSA. On the other hand ligand substitution in TPC, where the platinum is bonded to nitrogen $\left[\left(\mathrm{NH}_{3}\right)_{4} \mathrm{Pt}\right]^{2+}$, is extremely slow, ${ }^{12}$ and so no platinum antigen is formed as a result of normal occupational exposure. Preliminary results of this study were submitted to the Advisory Committee on Toxic Substances when the exposure limit for soluble platinum salts was under consideration and subsequently the maximum exposure limit has been restricted to the halogeno complex salts of platinum. ${ }^{17}$

When toxic properties of metal compounds are being considered by regulatory bodies there is a tendency for generic classification to be applied to all compounds of a particular metal which ignores the very major differences in toxicity shown by the various compounds the chemical formulas of which may look superficially similar. Toxicity is usually related to reactivity and this study emphasises the need to differentiate the chemical species of metal compounds when exposure standards are set.

The medical surveillance programme was initiated by Dr E G Hughes and continued by the late Dr Morag Stewart until 1991 and since then by Dr P J Linnett. Dr John Fry and Mr Peter Lee of P N Lee Statistics and Computing performed the statistical analysis. The study was funded by Johnson Matthey.

1 Hunter D, Milton R, Perry KMA. Asthma caused by the complex salts of platinum. Br f Ind Med 1945;2:92-8.

2 Roberts AE. Platinosis: five year study of the effects of soluble platinum salts on employees in a platinum laboratory and refinery. Archives of Industrial Hygiene and Occupational Medicine 1951:4:549-59.

3 Baker DB, Gann PH, Brooks SM, et al. Cross-sectional study of platinum salts sensitization among precious metals refinery workers. Am f Ind Med 1990;18:653-64.

4 Bolm-Audorf U, Bienfait HG, Burkhard J, et al. Prevalence of respiratory allergy in a platinum refinery. Int Arch Occup of respiratory allergy in a platinum
Environ Health 1992;64:257-60.

5 Venables KM, Dally MB, Nunn AJ, et al. Smoking and Venables KM, Dally $\mathrm{MB}$, Nunn AJ, et al. Smoking and
occupational allergy in workers in a platinum refinery. $B M \mathcal{F}$ 1989;299:939-42.

6 Calverly AE, Rees D, Dowdeswell RJ, et al. Platinum salt sensitivity in refinery workers: incidence and effects of smoking and exposure. Occup Environ Med 1995;52:661-6.

7 Niezborala M, Garnier G. Allergy to complex platinum salts: a historical prospective cohort study. Occup Environ Med 1996;53:252-7.

8 Freedman SO, Krupey J. Respiratory allergy caused by platinum salts. F Allergy 1968;42:233-7.

9 Pepys J, Pickering CAC, Hughes EG. Asthma due to inhaled chemical agents: complex salts of platinum. Clin Allergy 1972;2:391-6.

10 Hughes EG. Medical surveillance of platinum refinery workers. Fournal of the Society of Occupational Medicine 1980:30:27-30.

11 Health and Safety Executive. The medical monitoring of workers exposed to platinum salts. London: Health and Safety ers exposed to platinum salts. London: He

12 Cleare MJ, Hughes EG, Jacoby B, et al. Immediate (type I) allergic responses to platinum compounds. Clin Allergy 976;6:183-95.

13 Health and Safety Executive. Method for the determination of hazardous substances. Platinum metal and soluble platinum compounds in air. London: Health and Safety Executive; 1996. (Guidance Note MDHS 46/2.)

14 Meldrum M, Northage C, Howe A, et al. Platinum metal and soluble platinum salts. Criteria document for an occupational exposure limit. London: Health and Safety Executive, 1996.

15 Linnett PJ. Platinum salt sensitivity: a review of the health aspects of platinum refining in South Africa. Fournal of the Mine Medical Officers Association of South Africa 1987;63. $24-8$.

16 Grootveld MC. Studies of the immunochemistry of platinum complexes: the interaction of $\left(\mathrm{PtCl}_{4}\right)^{2-}$ and $\left(\mathrm{PtCl}_{6}\right)^{2-}$ with human serum albumin [PhD thesis]. London: London University, 1985 .

17 Health and Safety Executive. Occupational Exposure Limits 1997. London: Health and Safety Executive, 1997. (EH40/ 97.) 